Justin Clarke-Doane

Columbia University

[This is a penultimate draft of a paper that is forthcoming in a special issue of Synthese.]

\title{
Metaphysical and Absolute Possibility ${ }^{1}$
}

It is widely alleged that metaphysical possibility is "absolute" possibility (Kripke [1980], Lewis [1986], Rosen [2006, 16], Stalnaker [2005, 203], Williamson [2016, 460]). Indeed, this is arguably its metaphysical significance. Kripke calls metaphysical necessity "necessity in the highest degree" ([1980, 99]). Williamson calls metaphysical possibility the "maximal objective modality" [2016, 459]. Rosen says that "metaphysical possibility is the [most inclusive] sort of real possibility" ([2006, 16]). And Stalnaker writes, "we can agree with Frank Jackson, David Chalmers, Saul Kripke, David Lewis, and most others who allow themselves to talk about possible worlds at all, that metaphysical necessity is necessity in the widest sense" [2003, 203]. ${ }^{2}$

What exactly does the thesis that metaphysical possibility is absolute amount to? Is it true? In this article, I argue that, assuming that the thesis is not merely terminological, and lacking in any

\footnotetext{
${ }^{1}$ Thanks to Derek von Barandy, Martin Glazier, Max Khan Hayward, Ian Rumfitt, Alex Silk, Juhani Yli Vakkuri, and two anonymous referees for comments.

${ }^{2}$ Chalmers writes, "the metaphysically possible worlds are just the logically possible worlds [1996, 38]", where logical possibility, in turn, is "possibility in the broadest sense [1996, 35]." Similarly, Murray and Wilson note that "[m]etaphysical necessity and possibility are commonly supposed to be necessity and possibility in the broadest...sense $[2012,189]$." They then quote John Burgess as writing, "we may distinguish the species of physical necessity, or what could not have been otherwise so long as the laws of nature remained the same, from metaphysical necessity, what could not have been otherwise no matter what $[2009,46]$." (Note that Murray and Wilson also reject the orthodoxy that metaphysical necessity is absolute, but for a very different reason. They hold that "metaphysical necessities and possibilities are relativized to indicative actualities" [Murray and Wilson, 189].)
} 
metaphysical interest, it is an article of faith. I conclude with the suggestion that metaphysical possibility may lack the metaphysical significance that is widely attributed to it.

\section{Absolute Possibility}

What is metaphysical necessity? Perhaps the most informative characterization lists the metaphysical necessities directly. It is supposed to be metaphysically necessary that there are infinitely-many prime numbers, that you have the parents that you have, and that Hesperus = Phosphorus -- at least assuming the actual facts about the prime numbers, your parents, and Hesperus. Plantinga tells us,

[W]e must give examples and hope for the best....[T]ruths of propositional logic and first order quantification theory....are necessary....But the sense of necessity in question...is wider than this. Truths of set theory, arithmetic and mathematics generally are necessary in this sense, as are a host of homelier items such as

No one is taller than himself

Red is a colour

If a thing is red, then it is coloured

No numbers are human beings and No prime minister is a prime number. So the sense of necessity in question is wider than that captured in first order logic. On the other hand, it is narrower than that of causal or natural necessity [1972, 1-2].

Similarly, Sider writes, 
We are told that logic...is metaphysically necessary. We are told that laws of nature are not....[I]t is metaphysically necessary that "nothing can be in two places at once", and so on. This conception falls far short of a full criterion. But a thin conception is not in itself problematic....[O]ne often assumes that the facts involving [a] notion will outrun one's conception $[2011,266]$.

Perhaps the most important feature of metaphysical necessity is supposed to be that it is “absolute" necessity (Kripke [1980], Lewis [1986], Rosen [2006, 16], Stalnaker [2005, 203], Vetter [2016, 774]), Williamson [2016, 460]). It is “maximal” (Williamson [2016, 459]) necessity, necessity "in the highest degree" ([1980, 99]), and "in the widest sense" (Stalnaker [2003, 203]). Some even come close to defining metaphysical necessity as absolute necessity (Williamson [2016]). But this is unwise. The fact that metaphysical necessity is absolute is supposed to be a metaphysically significant fact. But if one simply defines it this way, then it is terminological. Given a prior understanding of "absolute", the stipulation that metaphysical necessity is absolute necessity no longer implies, for instance, that it is absolutely necessary that there are infinitely-many prime numbers, that Hesperus $=$ Phosphorus, or that you have the parents that you have -- even assuming the actual facts about numbers, Hesperus, and you.

What exactly does the thesis that metaphysical necessity is absolute amount to? It is not hard to say what it amounts to at first approximation. It amounts to the thesis that metaphysical necessity is the most restrictive notion of necessity. Correlatively, it amounts to the thesis that 
metaphysical possibility is the most inclusive notion of possibility (Hale [1990]). If $<>_{M}$ is metaphysical possibility, then, for any proposition, $\mathrm{P}$, and for any notion of possibility, $>_{\mathrm{N}}$, if $\diamond_{\mathrm{N}} \mathrm{P}$, then $\succ_{\mathrm{M}} \mathrm{P}$, but perhaps not conversely. Or, if []$_{\mathrm{M}}$ is metaphysical necessity, and $\diamond \mathrm{P} \longleftrightarrow \longrightarrow$ $\sim[] \sim \mathrm{P}$, then, for any notion of necessity, []$_{N}$, if []$_{\mathrm{M}} \mathrm{P}$, then []$_{\mathrm{N}} \mathrm{P}$, but perhaps not conversely.

The above explanation of the thesis that metaphysical possibility is absolute only an approximation because it is unclear what counts as a "notion of possibility" in the relevant sense. ${ }^{3}$ Metaphysical possibility is certainly not the most inclusive interpretation of the symbol $\prec$ that one finds in modal logic textbooks. For instance, select notions of doxastic possibility are more inclusive than metaphysical possibility. It is doxastically possible (for some agent) that there are not infinitely-many prime numbers, but it is not metaphysically possible that this is so.

There is a standard way of clarifying the thesis that metaphysical possibility is absolute, however. Of course, metaphysical possibility is not the most inclusive interpretation of the symbol $\diamond$. But that is because, like doxastic possibility, such interpretations may be merely epistemic, concerning knowledge or beliefs, or deontic, concerning norms of various sorts. The thesis that metaphysical possibility is absolute should, accordingly, be taken to be the thesis that metaphysical possibility is the most inclusive non-epistemic, non-deontic notion of possibility.

But this thesis is false. Consider logical possibility. In particular, consider the notion of logical possibility corresponding to some fixed S5 system of quantified modal logic with contingent

\footnotetext{
${ }^{3}$ I will switch between talk of necessity and possibility when this is natural, and the difference is unimportant.
} 
identify (such as those discussed in Girle $\left[2017,7.4,8.5, \&\right.$ 8.6] or Priest [2008, Ch. 17]). ${ }^{4}$ Then

this notion is neither epistemic nor deontic in the above senses. It is no more defined in terms of concepts like knowledge, belief, justification, obligation, or permission, than is metaphysical possibility. To say that it is logically possible that $\mathrm{P}$ in this sense is just to say that "things might (logically)...have been" such that P ([Rumfitt [2010, fn. 21]). It is not to say, e.g., that, for all we know, or for all we could know a priori, it is the case that P. As Rumfitt writes, "[t]here seems to be no reason to suppose that any statement that is logically necessary....is knowable $a$ priori $\left[\right.$ or i] ndeed....knowable at all" $([2010,44]) .^{5}$ And while one could just decide to use the term "epistemic" so that logical possibility in this sense counts as epistemic, that would make the thesis that metaphysical possibility is the most inclusive non-epistemic notion of possibility terminological. Logical possibility in the present sense is dramatically more inclusive than metaphysical possibility. It is logically possible in the present sense that you could have had different parents, that Hesperus $\neq$ Phosphorus, and that there are not infinitely-many prime numbers - even assuming the actual facts about you, Hesperus, and the numbers.

Of course, the notions of logical possibility above are not the only ones available. For instance, the corresponding languages do not include indexicals, and the systems validate Necessitation,

\footnotetext{
${ }^{4}$ Note that some such notions do not entail the necessity of all classical logical truths. For instance, notions based on free logic do not have the consequence that [] $\exists x(x=a)$, for a name in the language, 'a' (see, again, Girle [2017, 8.6]).

${ }^{5}$ This is especially clear when we consider higher-order logics, which lack sound and complete proof systems. (Rumfitt is focused on "broadly" logical necessity, according to which, while such things as that all bachelors are unmarried are logically necessary, that water $=\mathrm{H}_{2} 0$ is not. The considerations he adduces for regarding his notion of logical possibility as non-epistemic seem to me to serve equally to show that the present notion is non-epistemic. But if one were peculiarly suspicious of the notions of logical possibility to which I appeal, then my point that metaphysical possibility is not the most inclusive non-epistemic notion of possibility could be made equally by appealing to Rumfitt's.)
} 
unlike that of Kaplan [1989a]. ${ }^{6}$ This is as it should be. Having a true necessitation in Kaplan's system does not correspond to expressing a necessary truth. If ' $\mathrm{P}$ ' means 'It is raining', and A is an actuality operator, then, for Kaplan, []AP, yet $\sim[] \mathrm{P}$. But 'It is actually raining' no more expresses a necessary truth than 'It is raining' (Bostock [1988, Sec. II]). ${ }^{7}$ In order to refute the thesis that metaphysical possibility is the most inclusive non-epistemic notion of possibility, I do not need to show that every notion of logical possibility is more inclusive than metaphysical possibility. I need to show that at least one such notion is.

\section{"Real" Possibility}

It might be thought that the notions of logical possibility above can still be ruled out as irrelevant. The problem with epistemic and deontic notions of possibility is that they are not real or objective notions of possibility, and it might be claimed that there are other ways of failing to be real or objective than being epistemic or deontic. ${ }^{8}$ Again, Rosen is explicit that "metaphysical possibility is the [most inclusive] sort of real possibility" ([2006, 16, my emphasis]) and Williamson claims that metaphysical possibility is the "maximal objective modality" [2016, 459, my emphasis].

But what is a "real" or "objective" notion of possibility? Strohminger and Yli-Vakkuri tell us that "[p]erhaps the most straightforward way to characterize objective modality is negatively: it

\footnotetext{
${ }^{6}$ Thanks to an anonymous referee for pointing this out.

${ }^{7}$ Thanks to Rumfitt for emphasizing this to me. Moreover, if we want the system in question to assign truth-values to propositions, rather than to sentences, then Kaplan's system with indexicals seems inapt. Kaplan himself notes that validity in his system "states a property of sentences", rather than "of... a proposition" ([1989b, 596]). (Thanks to Alex Silk for discussion.)

${ }^{8}$ Kment [2016] uses "ontic" and Hale [2013] uses "alethic" to the same effect. Using "alethic" in this way is misleading, however, since the term normally used to mean satisfies the Taxiom. More on this below.
} 
is what the modal words express when they are not used in any epistemic or deontic sense..."

$[2017,825$, emphasis in original]. But this just returns us to the thesis that metaphysical

possibility is the most inclusive non-epistemic, non-deontic notion of possibility, which we have already seen is false.

Maybe we should also require that "real" or "objective" notions of possibility are alethic in sense of satisfying the axiom, $(T)[] P \rightarrow P$ ? This would not help. The notions of logical possibility described above are alethic in this sense. Indeed, they satisfy all of the axioms of S5 modal logic.

Williamson suggests that objective (or real) notions of possibility are also "not sensitive to the guises under which the objects, properties, relations and states of affairs at issue are presented" [2016, 454]. Hence, "identity [and distinctness are] simply objectively necessary..." [2016, 454]. For Williamson, then, the thesis that metaphysical possibility is absolute possibility at least amounts to the thesis that metaphysical possibility is the most inclusive alethic, non-epistemic, non-deontic notion of possibility which validates the Necessity of Identity and Distinctness.

\footnotetext{
${ }^{9}$ Although it is sometimes alleged that contingent identity is simply unintelligible, Kripke's argument for the Necessity of Identity, in terms of rigid designation, seems to me weak. First, it assumes a possible worlds semantics, even though Kripke is explicit that possible worlds merely afford a "metaphor" [1971, 174]. What is the argument, stripped of the metaphor? Second, as Cameron [2006] observes, Kripke appears to equivocate with the term "rigid designator". If to say that names are rigid designators is just to say that, e.g., "Hesperus" and "Phosphorus" refer to what they actually refer to in every world, then showing that "Hesperus" and "Phosphorus" are rigid designators does nothing to show that the terms co-refer at every world. It merely shows that "Hesperus" refers to Hesperus in every world, and that "Phosphorus" refers to Phosphorus in every world, leaving open whether they ever refer to different objects in a world. On the other hand, if it means that "Hesperus" and "Phosphorus" co-refer in every world, given that they do in the actual world, then Kripke assumes what he seeks to prove. Either way, it is misleading to contend that "[i]f names are rigid designators, then there can be no question about identities
} 
But this still cannot be right. Metaphysical possibility is not the most inclusive such notion. We can define a more inclusive one by amending the notion of logical possibility above so as to validate the Necessity of Identity and Distinctness (see, e.g., Priest [2008, 16.2 \& 16.3]). Then, while it is indeed necessary in the resulting sense that Hesperus $=$ Phosphorus (given that, in fact, Hesperus $=$ Phosphorus), it is still not necessary that you have the parents that you have.

(Actually, assuming Kripke's weak reading of [] according to which "[w]e...count statements as necessary if whenever the objects mentioned therein exist, the statement would be true" [Kripke 1971, 137], it is really only necessary that if Hesperus exists, then Hesperus = Phosphorus.) Needless to say, in this case, as well, no existentially quantified mathematical truths will count as necessary either. ${ }^{10}$

Maybe metaphysical possibility is the most inclusive notion of "real" possibility in the sense of being the most inclusive alethic, non-epistemic, non-deontic notion which satisfies some more overtly metaphysical condition. For instance, perhaps it is the most inclusive such notion that corresponds to the concrete worlds of Lewis [1986], or is "grounded in the nature of things" (Fine [2002]), or is explained in terms of their dispositions (Vetter [2015], [2016]). But if that were right, then only Lewisian, Finean or Vetterian realists would be in a position to accept the

being necessary ([Kripke 1971, 181])". (Note that $\forall \mathrm{x} \forall \mathrm{y}(\mathrm{x}=\mathrm{y} \rightarrow[](\mathrm{x}=\mathrm{y})$ ) is certainly not self-evident, given that it is apparently false if [] means, e.g., it is known that.) See Cartwright [1997] for a more careful treatment. ${ }^{10}$ Williamson is explicit that the mathematical truths are metaphysically necessary (as is Kripke [1980, 37]). For instance, he says that "the structure of the hierarchy of pure sets... seems to be a metaphysically noncontingent matter" [2017, 199]. See also his [2016, 454]. 
orthodoxy that metaphysical possibility is absolute. ${ }^{11}$ In particular, none of the authors

mentioned above -- including Williamson, Stalnaker, Jackson, Kripke, and Chalmers -- would

be. It might be responded that such authors could "piggy back" on the theories of Fine, Vetter, and Lewis. For instance, they might claim that $\mathrm{P}$ is a real possibility just when, e.g., according to Lewis's theory of worlds, there is a concrete world in which $\mathrm{P} .^{12}$ However, in that case the claim that metaphysical possibility is absolute would lack the significance it is supposed to have. After all, we could equally introduce an alternative theory, $T^{*}$, like Lewis's, except that, according to $\mathrm{T}^{*}$, there are concrete worlds in which, e.g., there are not infinitely-many prime numbers. We could then say that $\mathrm{P}$ is a real* possibility just when, according to $\mathrm{T}^{*}$, there is a concrete world in which P. And we could add that a notion of possibility is absolute* just when it is the most inclusive notion of real* possibility. Even if metaphysical possibility is absolute (something that I argue in [Forthcoming A] that even a Lewisian should deny), this conclusion seems terminological, lacking in metaphysical interest, absent some reason to privilege absoluteness over absoluteness*. ${ }^{13}$

\footnotetext{
${ }^{11}$ There are independent problems with each of these proposals. For instance, assuming, contra Anselm, that nature does not "precedes existence", so that it cannot be part of numbers' nature to exist, there are notions of possibility that are grounded in the nature of things, but according to which there could have failed to be any numbers.

${ }^{12}$ Thanks to an anonymous reviewer for suggesting this proposal.

${ }^{13}$ This is one objection I have to the "modal fictionalism" of Rosen [1990], which takes something like the above form. (Actually, I suspect that a version of the objection just considered arises for Lewisans, Fineans, and Vetterians themselves. For example, even if it is "grounded in the nature of things" that you have the parents that you have, we could always introduce a notion of nature*, which is like nature, except that, e.g., it is no part of your nature* that you have the parents that you have. We could then say that something is metaphysically* necessary just when it is grounded in the nature* of things. Defining absolute* as before, what does it matter that metaphysical possibility is absolute, given that it is not absolute*? In fact, we could raise a similar problem by continuing to speak only of natures, but introducing a notion of ground*. See my [Forthcoming A, Sec. 6], [Forthcoming B, Conclusion], and [Forthcoming $\mathrm{C}$ ] for further discussion.)
} 
Perhaps metaphysical possibility is the most inclusive notion of "real" possibility in the sense of being the most inclusive natural, alethic, non-epistemic, non-deontic notion of possibility which satisfies the Necessity of Identify and Distinctness? Not in any familiar sense of "natural". The notions of logical possibility mentioned above are natural if anything is. They are perhaps the standard examples of alethic notions of possibility to which modal logic texts routinely appeal.

We might suggest that the above notions of logical possibility are not "natural" in the sense of being unqualified. ${ }^{14}$ As van Inwagen writes, if $\mathrm{P}$ is metaphysically possible, then it is possible "tout court. Possible simpliciter. Possible period.... possib[le] without qualification" [1997, 72]. But I am not aware of any non-question-begging argument that the notions of logical possibility above are qualified in a sense in which metaphysical possibility is not. One could try to define a given notion of logical possibility by saying, roughly, that $\mathrm{P}$ is logically possible when it is metaphysically possible or not a logical truth or falsehood. But this assumes the availability of a non-modal analysis of "logic" (Fine [2002, 237]), and advocates logical possibility, such as Balaguer [1995, 317] or Field [1989, Introduction], explicitly reject this assumption. ${ }^{15}$ Indeed, one could equally define metaphysical possibility as logical possibility, given the "laws of metaphysics" (Sider [2012, Ch. 12]). There are problems with this analysis. It threatens to trivialize the necessity of the metaphysical laws (Fine [2002]). Also, there may be metaphysical necessities not entailed by any metaphysical laws. ${ }^{16}$ But, arguably, this just shows that neither

\footnotetext{
${ }^{14}$ Thanks to an anonymous referee to highlighting the distinction between absoluteness (or "wideness") and unqualifiedness, a distinction which I had obscured in an prior draft.

${ }^{15}$ It just so happens that a first-order non-modal sentence is logically necessary when it is provable in any standard (sound and complete) proof system and true in all models.

${ }^{16}$ Thanks to an anonymous referee for pointing out the second ground for skepticism.
} 
notion can be analyzed in terms of the other. It does not show that we lack an unqualified notion of logical possibility.

\section{How the World Could Have Been Different}

Maybe we have been wrong to seek formal constraints on what counts as a "real" or "objective" notion of possibility. What matters is whether a notion of possibility concerns whether "the world should have been different from the way it is" [Kripke 1980, 36]. ${ }^{17}$ The thesis that metaphysical possibility is absolute in the sense of being the most inclusive notion whose possibilities satisfy condition $\mathrm{C}$ seems anemic absent an argument that the class of possibilities satisfying $\mathrm{C}$ is the most inclusive class of ways the world could have been different. For instance, if we stipulate, with Williamson, that "identity is simply objectively necessary..." [2016, 454], the substantive question just becomes whether the world could have failed to conform to the objective necessities. ${ }^{18}$ As Hale notes, the idea that "while it is...necessary that heat is mean kinetic energy of molecules [for example], there are possible worlds...in which this is not so" $[1996,98]$ is unsatisfying. For "what [one] wanted to maintain is that, given [that] heat is mean kinetic energy of molecules, there are no possible worlds in which heat is not so constituted" [1996, 98].

\footnotetext{
${ }^{17}$ This locution is slightly misleading, since what is actual is metaphysically possible. Similarly, "counterfactual" suggests counter-to-fact, but there is no problem counterfactually conditionalizing on what is actual.

${ }^{18}$ Sometimes Williamson suggests that notions of necessity which fail to satisfy the Necessity of Identity are not objective in the sense that they are not about the states-of-affairs described. They are at least partly about the words used to describe them. But this is tendentious. Advocates of contingent identity - such as Gibbard [1975], Wilson [1983], or Priest [2016] - should think that claims involving "Hesperus" and "Phosphorus" are about...Hesperus and Phosphorus! They may even allow that "Hesperus" and "Phosphorus" are rigid designators in the sense of picking out what they pick out in the actual world. In general, advocates of contingent identity should maintain that we may have $\mathrm{t}=\mathrm{t}$ ', but, also, []$(\ldots \mathrm{t} \ldots) \& \sim[]\left(\ldots \mathrm{t} \mathrm{t}^{\prime} ..\right)$, where “( ... $\left.\mathrm{x} \ldots\right)$ " is a formula with only $\mathrm{x}$ free, even though claims involving $t$ and $t$ ' are about the referents of $t$ and $t$ '. (Gibbard, Wilson, and Priest are motivated by different examples than "Hesperus = Phosphorus", but an analogous point holds for the cases they consider.)
} 
One worry with the above proposal is that a "merely epistemic" notion of possibility might still concern whether "the world should have been different from the way it is". ${ }^{19}$ But what is the force of calling a notion of possibility which, like metaphysical possibility, concerns how the world could have been different - and, we can add, is natural, alethic, does not concern beliefs or knowledge, and so on - "merely epistemic"? Or, to put it differently, what makes the "non-epistemic" possibilities in this sense different from the epistemic ones, save their exclusivity? It is hard to see what could make a notion of possibility which "acts" just like metaphysical possibility, but is more inclusive, epistemic in any useful sense in which metaphysical possibility is not. ${ }^{20}$

Of course, Kripke's locution "should have been different" (or "could have been different") does not afford a reductive definition of real possibility. But I am not aware of any locution that uncontroversially does. ${ }^{21}$ Indeed, modal locutions are widely supposed to resist reduction. We might improve the definition somewhat by appeal to a technique of Bealer. He suggests translating the question of whether it is possible that $\mathrm{P}$ in the relevant sense into that of whether either $\mathrm{P}$ is true but noncontingent, or $\mathrm{P}$ is contingent $[2002,78]$. While this does not amount to a reductive definition of "real possibility" either, Bealer points out that "contingent" and "noncontingent" are almost exclusively used in the relevant sense, unlike "possible" and "necessary". What matters here is merely that such glosses are accurate as far as they go.

\footnotetext{
19 Thanks to an anonymous referee for pointing this out.

${ }^{20}$ Indeed, an anonymous referee pointed out that counterfactuals, to which Kripke, Williamson, and others routinely appeal when characterizing metaphysical possibility, are partly analyzed in apparently epistemic terms.

${ }^{21}$ The definition of Lewis [1986] is, of course, highly controversial.
} 
So, setting aside formal constraints, is metaphysical possibility at least the most inclusive notion of possibility that concerns how the world could have been different -- or, following Bealer, what is contingent? Again, evidently not. More inclusive notions of possibility in this sense, like the notions of logical possibility described above, are already studied under the heading "impossible worlds". Assuming an ontology of worlds, one identifies more inclusive notions of how the world could have been different with more inclusive classes of worlds (Kment [2014, 62-3], Priest [2016], Nolan [2012]). But this identification is not required, any more than is the identification of physical possibility with the class of physically possible worlds. In both cases, one option is to take the modal operators as primitive, like negation. ${ }^{22}$ Such notions explicitly concern how the world could have been - not, e.g., how it might be for all we know, or how it normatively may be. Kripke himself emphasizes that "'[p]ossible worlds' are stipulated, not discovered....There is no reason why we cannot stipulate that, in talking about what happened to Nixon in a certain counterfactual situation, we are talking about what would have happened to him" [1980, 267, italics in original]. Indeed, when talking about a logically possible, but metaphysically impossible, situation, such as what would have happened had Nixon had different parents, "there is no reason why we cannot stipulate that...we are talking about...him". 23

\footnotetext{
${ }^{22}$ Balaguer [1995, 317] and Field [1989, Introduction] take the notion of logical possibility as primitive. Melia [2003] discusses this approach more generally.

${ }^{23}$ Again, while one can interpret claims about what is logically possible as misleading claims about proofs or models, one can equally interpret claims of metaphysical possibility this way (where the "axioms" now include non-logical principles of mathematics, mereology, etc., as in Sider [2011, Ch. 12]). In both cases, we also have the option of interpreting the claims at face-value. (Actually, there are serious obstacles to even interpreting claims of logical possibility in this way. See Balaguer [1997, 317], Field [1989, Introduction] and Rumfitt [2010] \& [2015, Ch. 3].)
} 
But are not more inclusive notions of how the world could have been different, such as logical possibility, precisely notions of impossibility? Whatever we call them, the availability of such notions undercuts the thesis that metaphysical possibility is the most inclusive notion of how the world could have been different. On the contrary, metaphysical possibility seems to stand to logical possibility as physical possibility is widely supposed to stand to metaphysical possibility.

\section{$\underline{\text { Methodological Morals }}$}

Is there any other interesting sense in which metaphysical possibility might be absolute? I

cannot think of one. ${ }^{24}$ Metaphysical possibility is certainly not the most inclusive non-epistemic, non-deontic, notion of possibility. It is not even the most inclusive such notion which is natural, alethic, and validates the Necessity of Identity and Distinctness. Perhaps more importantly, setting aside formal constraints, it is not the most inclusive notion of how the world could have been different. In conclusion, let me discuss the broader ramifications of this result.

Ask a metaphysician whether something is possible or necessary, and you can assume that they will take you to be asking whether it is metaphysically possible or necessary. If metaphysical possibility were absolute possibility, then we could see why. An absolute notion of possibility

\footnotetext{
${ }^{24}$ Glazier suggests that real notions of necessity are those which support a certain kind of explanation. I suspect that this suggestion faces problems analogous to the suggestion that the real necessities are grounded in the nature of things. There are different notions of "explanation" giving rise to different notions of real necessity. But even if I am wrong, metaphysical possibility is not the most inclusive notion of real possibility by Glazier's criteria, since logical necessity is explanatory. See Glazier [Forthcoming]. (Thanks to Glazier for discussion.) Another pertinent discussion is that of Bacon [Forthcoming]. I have rejected his assumptions about what makes for a "modality" above. For instance, Bacon assumes that logical necessity is not a modality in the relevant sense, since it concerns sentences, not propositions. But this is tendentious. Advocates of logical necessity, such as Field [1989, Introduction] or Balaguer [1995, 317], treat the notion as applying to propositions. In any event, metaphysical possibility is not absolute by Bacon's lights either. (His "broadest" necessity does not even validate the Necessity of Distinctness or the S5 Axiom.) So, I set his discussion aside as well.
} 
would be like Godel's absolute - i.e., most inclusive - notion of set (Godel [1947]). It would constitute the "ultimate court of appeals" for questions of the relevant sort. Just as all notions of set could be understood as restrictions on the absolute notion, if there were one, all (counterfactual) notions of possibility could be understood as restrictions on metaphysical possibility. For any distinct notion of possibility and necessity, $\diamond_{\mathrm{N}}$ and []$_{N}$, we would have $\diamond_{\mathrm{N}} \mathrm{A} \leftarrow \diamond_{\mathrm{M}}(\mathrm{T} \& \mathrm{~A})$ and []$\left._{\mathrm{N}} \mathrm{A} \leftarrow\right]_{\mathrm{M}}(\mathrm{T} \rightarrow \mathrm{A})$, where $\succ_{\mathrm{M}}$ and []$_{\mathrm{M}}$ are metaphysical possibility and necessity, respectively, and $\mathrm{T}$ is the conjunction of uniquely $\mathrm{N}$-necessities (i.e., all P such that []$_{N} P$, and for any real notion of necessity, []$_{A}$, if $\left[\forall Q\left([]_{A} Q \rightarrow[]_{N} Q\right) \&\right.$ $\left.\sim \forall \mathrm{Q}\left([]_{\mathrm{N}} \mathrm{Q} \rightarrow[]_{\mathrm{A}} \mathrm{Q}\right)\right]$, then $\left.\sim[]_{\mathrm{A}} \mathrm{P}\right){ }^{25}$ For example, if metaphysical necessity were absolute, then it would be physically necessary that nothing travels faster than the speed of light just in case it was metaphysically necessary that nothing travels faster than the speed of light, given the laws of physics.

But if metaphysical possibility is not absolute, then it too is a restricted notion of possibility. This is not to say that it is uninteresting, or fails to "carve at the joints", contra Sider [2011, Ch. 12]. Godel's constructible notion of set (which restricts those notions satisfying the hypothesis of a Measurable Cardinal) is interesting and is "joint carving" if any notion of set is. But few who doubt the Axiom of Constructibility, $\mathrm{V}=\mathrm{L}$ (which says that all sets are constructible), would suggest that set theory should be centered on it. After all, it fails to give a comprehensive picture of the universe of sets. Similarly, if metaphysical possibility is not absolute, then it becomes harder to see why modal metaphysics should be centered on it. Various notions of

\footnotetext{
${ }^{25}$ Although this is the standard view, it can be questioned. See Van Fraassen [1977] and Fine [2002]. (Note that T may not be a finite conjunction, so I am not working in a typical modal language here.)
} 
logical possibility, with or without the Necessity of Identity and Distinctness, are also interesting and joint carving. Philosophers have long appealed to something like them. And they give a more comprehensive picture of the ways the world could have been.

Note that I have not argued that any of the above notions of logical possibility is absolute. I regard the question of whether there is an absolute notion of possibility, as opposed to, say, an infinite sequence of ever more inclusive ones, as open (Nolan [2011, 317], Sider [2012, 282], [Clarke-Doane, Forthcoming, Sec. 8], [Rayo, Manuscript]). ${ }^{26}$ And I regard the question of whether, given that there is an absolute notion of possibility, it validates anything of traditional metaphysical interest, as open too (Mortensen [1989]). But I submit that if there is an absolute notion of possibility, then modal metaphysics should be centered on it. That metaphysicians implicitly agree is evinced by their eagerness to affirm the absoluteness of metaphysical possibility. We need not cease studying the notion of metaphysical possibility. But it should be studied in the spirit that skeptics of $\mathrm{V}=\mathrm{L}$ study the constructible notion of set - as one of many natural restrictions that one can draw.

\section{Bibliography}

Bacon, Andrew. [Forthcoming] "The Broadest Necessity." Journal of Philosophical Logic. Balaguer, Mark. [1995] Platonism and Anti-Platonism in Mathematics. New York: Oxford University Press.

Bealer, George. [2002] "Modal Epistemology and the Rationalist Renaissance." in Gendler and Hawthorne (Eds.).

Berto, Francesco, "Impossible Worlds", The Stanford Encyclopedia of Philosophy (Winter 2013 Edition), Edward N. Zalta (ed.), URL =

$<$ https://plato.stanford.edu/archives/win2013/entries/impossible-worlds/>. Bostock, David, [1988] "Necessary Truth and A Priori Truth.” Mind. Vol. 49. 343-397.

\footnotetext{
${ }^{26}$ Nolan [2011] identifies notions of possibility with classes of worlds, and understands worlds as Lewis's "ersatz" worlds, such as arbitrary sets of sentences. But this trivializes the question of absoluteness. Given these stipulations, metaphysical possibility is trivially not absolute, and the notion of Mortensen [1989], according to which literally anything is possible, trivially is.
} 
Burgess, John. [2009] Philosophical Logic. Princeton: Princeton University Press.

Cameron, Ross. [2006] "Comment on 'Kripke's (Alleged) Argument for the Necessity of Identity Statements'." Wo's Weblog. Online at: <

https:/www.umsu.de/wo/archive/2006/08/09/Kripke s Alleged Argument for the Necessit

$\mathrm{y}$ of Identity Statements>

Cartwright, Richard. [1997] "On Singular Propositions.” Canadian Journal of Philosophy.

Supplementary Volume 23. 67-83.

Chalmers, David. [1996] The Conscious Mind. New York: Oxford University Press.

-----. [2002] "Does Conceivability Entail Possibility?” in Tamar Gendler and John Hawthorne

(eds.), Conceivability and Possibility. New York: Oxford University Press. 145-200.

Clarke-Doane, Justin. [Forthcoming A] "Modal Objectivity." Nous.

-----. [Forthcoming B] Morality and Mathematics. Oxford: Oxford University Press.

-----. [Forthcoming C] "Objectivity and Evaluation.” Christopher Cowie and Richard Rowland

(eds.), Companions in Guilt Arguments in Metaethics. Routledge.

Field, Hartry. [1989] Realism, Mathematics, and Modality. Oxford: Blackwell.

-----. [1993] "The Conceptual Contingency of Mathematical Objects.” Mind. Vol. 102. 285-289.

Fine, Kit. [1994] "Essence and Modality.” In J.E. Tomberlin (ed.), Philosophical Perspectives,

Vol. 8. Oxford: Blackwell.

----. [2002] "The Varieties of Necessity." in Gendler and Hawthorne (Eds.).

Gendler, Tamar, and John Hawthorne (Eds.). [2002] Conceivability and Possibility. New York:

Oxford University Press.

Gibbard, Alan. [1975] "Contingent Identity.” Journal of Philosophical Logic. Vol. 4. 187-221.

Girle, Rod. [2017] Modal Logics and Philosophy (2 ${ }^{\text {nd }}$ Edition). Chicago: McGill-Queens

University Press.

Glazier, Martin. [Forthcoming] "The Difference Between Epistemic and Metaphysical

Necessity." Synthese.

Godel, Kurt. [1947] "What is Cantor's Continuum Problem?" American Mathematical Monthly.

Vol. 54. 515-525.

Hale, Bob. [1996] “Absolute Necessities.” Philosophical Perspectives. Vo. 10. 93-117.

-----. [2012] "Basic Logical Knowledge." in O'Hear (Ed.).

-----. [2013] Necessary Beings: An Essay on Ontology, Modality and the Relations Between

Them. Oxford: Oxford University Press.

Kaplan, David. [1989a] "Demonstratives." in Joseph Almog, John Perry \& Howard Wettstein (eds.), Themes From Kaplan. Oxford University Press.

-----. [1989b] “Afterthoughts." in Almog, Perry \& Wettstein (eds.).

Kment, Boris. [2014] Modality and Explanatory Reasoning. Oxford: Oxford University Press.

Kripke, Saul. [1971] "Identity and Necessity." in Milton K. Munitz, ed., Identity and

Individuation, New York University Press, New York, 161-191

-----. [1980] Naming and Necessity. Cambridge: Harvard University Press

Lewis, David. [1986] On the Plurality of Worlds. Oxford: Blackwell.

Lowe, E.J. [2012] "What is the Source of Our Knowledge of Modal Truths?" Mind. Vol. 121. 919-950.

Melia, Joseph. [2003] Modality. New York: Acumen.

Murray, Adam and Jessica Wilson. [2012] "Relativized Metaphysical Modality." in Bennett, Karen and Dean Zimmerman (eds.). Oxford Studies in Metaphysics. Oxford University Press. 
Mortensen, Chris. [1989] “Anything is Possible.” Erkenntnis. Vol. 30. 319-337.

Nolan, Daniel. [2011] "The Extent of Metaphysical Necessity." Philosophical Perspectives. Vol. 25. 313-339.

O’Hear, Anthony (Ed.). [2002] Logic, Thought, and Language. Cambridge: Cambridge

University Press.

Priest, Graham. [2008] An Introduction to Non-Classical Logic: From If to Is (2 ${ }^{\text {nd }}$ Edition). New York: Cambridge University Press.

-----. [2016] "Thinking the Impossible.” Philosophical Studies. Vol. 10. 2649-2662.

Quine, W.V.O. [1947] "The Problem of Interpreting Modal Logic.” Journal of Symbolic Logic.

Vol. 12. 43-48.

Rayo, Agustin. [Manuscript] "The Open-Endedness of Logical Space."

Rosen, Gideon. [1990] "Modal Fictionalism.” Mind. Vol. 99. 327-354.

-----. [2002] "A Study of Modal Deviance.” in Tamar Szabo Gendler and John Hawthorne (eds.),

Conceivability and Possibility. Oxford: Clarendon.

Rumfitt, Ian. [2010] "Logical Necessity." in Bob Hale \& Aviv Hoffmann (eds.), Modality:

Metaphysics, Logic, and Epistemology. Oxford: Oxford University Press.

-----. [2015] The Boundary Stones of Thought: An Essay in the Philosophy of Logic. Oxford:

Oxford University Press.

Russell, Bertrand. [1919] Introduction to Mathematical Philosophy. New York: The MacMillan

Co. Available online at: http://people.umass.edu/klement/imp/imp.html

Sider, Ted. [2011] Writing the Book of the World. New York: Oxford University Press

Stalnaker, Robert. [2003] "Conceptual Truth and Metaphysical Necessity" in Stalnaker, Robert, Ways a World Might Be. Oxford: OUP. 201-215.

Strohminger, Margot and Juhani Yli-Vakkuri. [2017] "The Epistemology of Modality." Analysis. Vol. 77. 825-838.

Van Fraassen, Bas. [1997] "The Only Necessity is Verbal Necessity." Journal of Philosophy. Vol. 74. 71-85.

Van Inwagen, Peter. [1997]“Modal Epistemology”. Philosophical Studies. Vol. 92. 68-84.

Vetter, Barbara. [2015] Potentiality: From Dispositions to Modality. Oxford: Oxford University Press.

-----. [2016] "Williamsonian Modal Epistemology, Possibility-Based." Canadian Journal of

Philosophy. Vol. 46. 766-795.

Wang, Jennifer. [2015] "The Modal Limits of Dispositionalism." Nous. Vol. 49. 454 - 469.

Williamson, Timothy. [2016] "Modal Science." Canadian Journal of Philosophy. Vol. 46. 453-492.

-----. [2017] "Counterpossibles in Semantics and Metaphysics.” Argumenta. Vol. 2. 195-226.

-----. [Forthcoming] "Counterpossibles." in Brad Armour-Garb and Fred Kroon (eds.),

Philosophical Fictionalism.

Wilson, Mark. [1983] "Why Contingent Identity is Necessary." Philosophical Studies. Vol. 43. 301-327. 